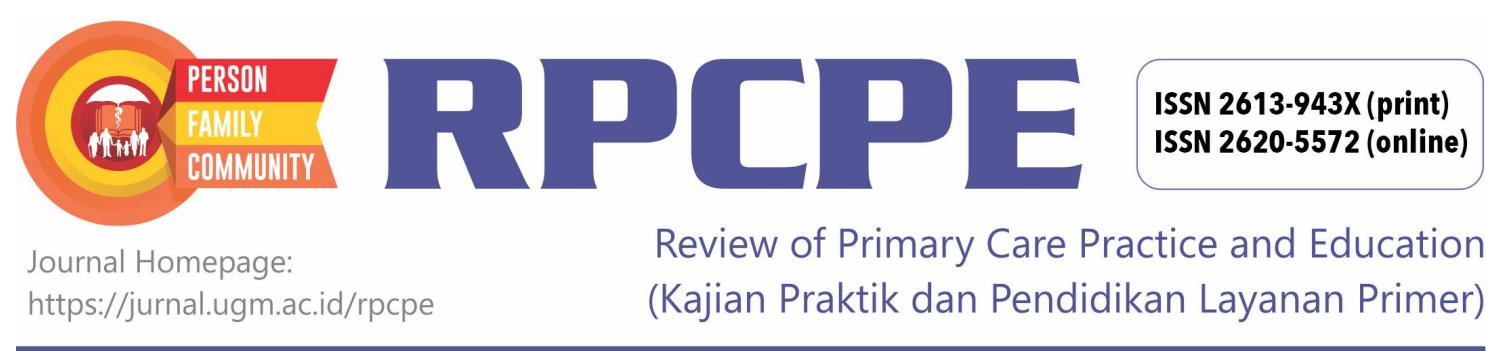

\title{
Advanced Life Support in Obstetrics
}

\author{
Lisa Soldat ${ }^{1}$ \\ ${ }^{1}$ Department of Family Medicine; University of Iowa; United State of America \\ Corresponding Author: \\ Lisa Soldat: Adjunct Faculty Member at Department of Family Medicine; University of Iowa; United State of America, Pomerantz \\ Family Pavilion, Iowa City, IA 52242, United States of America. \\ To cite this article: \\ Soldat L. Advanced life support in obstetrics. Rev Prim Care Prac and Educ. 2019; 2(2): 49-51.
}

\section{INTRODUCTION}

Multiple barriers to high quality maternity care have been identified in Indonesia. One barrier is the shortage of welltrained maternity care providers, particularly in remote and rural areas. Maternity care training programs do not consistently prepare their graduates to provide high quality care. Poor pre-service training may then be compounded by a lack of post-service supervision and inadequate multispecialty teamwork. Maternity care continuing education is an important means to reinforce and improve the skills needed to provide high quality maternity care. Programs that have been developed for low- to middleincome countries focus on providing culturally appropriate information to improve competency, communication and teamwork. Improvement in quality of care has been documented, showing a decrease in maternal morbidity and mortality. This trend is reflected in improvements in patient satisfaction and trust, and ultimately supports the tenets of patient-centered care.

\section{DISCUSSION}

A pregnant 24-year old woman arrived to a Puskesmas, complaining of abdominal pain. She has been seeing the traditional birth attendant in her village. She thinks she ought to deliver next month. She has had some vaginal bleeding off and on for two weeks without improvement and is worried there is something wrong. In the Puskesmas, the midwives are busy with two women in labor, and the primary care physicians are just finished seeing patients for the day. How do you decide if this woman's problem is an emergency? Who should evaluate her? And when?

Worldwide, as in Indonesia, the most common causes of maternal mortality are postpartum hemorrhage, hypertensive disorders, prolonged labor, complications from unsafe abortion and infection. The risks of maternal near miss and mortality are highest during labor, delivery and the immediate postpartum period ${ }^{1}$.

A significant barrier to decreasing maternal morbidity and mortality is the shortage of well-trained, clinically competent midwives, physicians and nurses, i.e., skilled birth attendants (SBAs) ${ }^{2}$. According to the WHO, a SBA should be competent in "the skills needed to manage normal (uncomplicated) pregnancies, childbirth and the immediate postnatal period, and in the identification, management and referral of complications in women and newborns ${ }^{3}$.

In 2017, a Cochrane review ${ }^{4}$ in low- and middle-income countries found moderate to high quality evidence that poor quality of SBA training programs gives rise to decreased competency and lower quality of care.

Additionally, there was moderate to high quality evidence for the importance of on-the-job training and supervision of SBAs after they enter the workforce.

A 2013 study of the quality of Indonesian midwife training determined that it was insufficient to consistently produce competent $\mathrm{SBAs}^{5}$. In this report, $28-52 \%$ of midwives were unable to actively manage the third stage of labor, measure blood pressure or identify the presenting part of the fetus, among other aspects.

There is a wide variability of SBA clinical and procedural competency in multiple areas ${ }^{6}$, such as:

1. Competency in common clinical skills, such as assisted vaginal delivery, nonpharmacological pain management, and delivery positions;

2. Ability to recognize and address risk factors for maternal complications, such as elevated blood pressure or anemia;

3. Ability to recognize and manage obstetrical emergencies, such as postpartum hemorrhage or preeclampsia/eclampsia;

4. Inconsistent application of standardized clinical protocols; and

5. Recognition of which complications can be managed locally and which necessitate timely referral to a tertiary care facility. 
Effective interprofessional communication and teamwork are equally important as procedural competency ${ }^{7}$. Acute obstetrical emergencies require immediate involvement of all members of the maternity care team. Poor communication leads to delays in instituting appropriate triage, management and can prevent timely referral to tertiary care facilities.

The value of maternity care continuing professional education cannot be overstated. It reinforces and improves learners' procedural and decision-making, skills. It also facilitates incorporation of current standards of care into daily practice.

What makes a maternity care continuing education program successful? It must provide educational material that is culturally relevant and evidence-based. It must be cost-effective ${ }^{8}$, and available in a format that minimizes the time spent away from clinical duties. Use of simulationbased training improves and reinforces clinical skills 9 . Programs are often designed to be understandable and applicable to all members of the multispecialty team. This interprofessional education (IPE) format allows learners to understand the importance of each other's roles, building respect and enhancing communication ${ }^{7,10}$.

One example of a popular maternity care training program is the Advanced Life Support in Obstetrics (ALSOÒ) Course $^{11}$. This program is owned and operated by the American Academy of Family Practice, and has been taught in over 62 countries for more than 25 years. The course content is managed and updated by a multispecialty editorial team, consisting of perinatologists, obstetricians, midwives and family physicians. The original curriculum is also available in a modified form (Global ALSO $\AA$ ) that is adapted for use in low- and middle-income countries. Global ALSO $®$ includes additional topics of cultural and epidemiologic relevance.

The ALSO ${ }^{\circledR}$ curriculum is applicable to all members of the maternity care team, including physicians, resident physicians, midwives and nurses. The curriculum is standardized, evidence-based and uses an adult-centered learning format. Local maternity care providers who successfully complete the ALSO ${ }^{\circledR}$ Instructor course serve as faculty, and, using the teach-the-teacher model, students are encouraged to become future instructors ${ }^{12}$.

A blended learning style is used that combines online and live classroom teaching. Online materials include lectures, workshop demonstrations and interactive programs. Learners complete the online course material prior to attending the live course. The one-day course uses simulation-based group workstations to provide hands-on, team-based training. Workstation topics include shoulder dystocia, malpositions, emergency breech delivery, assisted vaginal delivery, maternal resuscitation and postpartum hemorrhage.

Group testing is performed using seven different emergency scenarios based upon real-life patient care situations. Group feedback is provided at the conclusion of the course, focusing on team safety behaviors and communication.

The benefits of the ALSOO course in low resource settings have been studied. One study reported clinical skills improvement, with an increased frequency in active management of the third stage of labor, use of episiotomy, decreased postpartum hemorrhage, and increased frequency of assisted vaginal delivery and decreased inhospital mortality ${ }^{13}$. Another study noted that both doctors and midwives perceived that Interprofessional Education was valuable for improving multispecialty collaboration and communication ${ }^{10}$.

Maternity care continuing education programs designed for all members of the maternity care can improve proficiency in clinical competency and quality of care. When maternity care teams improve their collaboration and communication skills, they build confidence in both themselves and their patients. Maternal morbidity and mortality are reduced, and the patient-centered care model is strengthened.

\section{REFERENCES}

1. Mawarti Y, Utarini A, Hakimi M. Maternal care quality in near miss and maternal mortality in an academic public tertiary hospital in Yogyakarta, Indonesia: a retrospective cohort study. BMC Pregnancy and Childbirth. 2017 Dec;17(1):149.

2. World Bank. "...and then she died": Indonesia Maternal Health Assessment (English). Washington, DC: World Bank. 2010. Available from: http://documents.worldbank.org/curated/ en/718951468040488082/and-then-she-died-Indonesia-maternalhealth-assessment

3. World Health Organization. Making pregnancy safer: the critical role of the skilled attendant: a joint statement by WHO, ICM and FIGO. Geneva: World Helath Organization. 2004.

4. Munabi-Babigumira S, Glenton C, Lewin S, Fretheim A, Nabudere H. Factors that influence the provision of intrapartum and postnatal care by skilled birth attendants in low-and middle-income countries: a qualitative evidence synthesis. Cochrane Database of Systematic Reviews. 2017(11).

5. National Research Council. Reducing maternal and neonatal mortality in indonesia: Saving lives, saving the future. National Academies Press. 2013 Dec 26.

6. Brooks MI, Thabrany H, Fox MP, Wirtz VJ, Feeley FG, Sabin LL. Health facility and skilled birth deliveries among poor women with Jamkesmas health insurance in Indonesia: a mixed-methods study. BMC Health Services Research. 2017 Dec;17(1):105.

7. Kumar A, Sturrock S, Wallace EM, Nestel D, Lucey D, Stoyles S, et al. Evaluation of learning from Practical Obstetric MultiProfessional Training and its impact on patient outcomes in Australia using Kirkpatrick's framework: A mixed methods study. BMJ Open. 2018 Feb 1;8(2):e017451.

8. Van de Ven J, Van Baaren GJ, Fransen AF, van Runnard Heimel PJ, Mol BW, Oei SG. Cost-effectiveness of simulation-based team training in obstetric emergencies (TOSTI study). European Journal of Obstetrics \& Gynecology and Reproductive Biology. 2017 Sep $1 ; 216: 130-7$.

9. Nelissen E, Ersdal H, Mduma E, Evjen-Olsen B, Twisk J, Broerse $\mathrm{J}$, et al. Clinical performance and patient outcome after simulation-based training in prevention and management of postpartum haemorrhage: An educational intervention study in a low-resource setting. BMC Pregnancy and Childbirth. 2017 Dec;17(1):301.

10. Walker L, Fetherston C, McMurray A. Perceptions of interprofessional education in the Australian Advanced Life Support in Obstetrics (ALSO) course. Family Medicine. 2015; 47(6):435-44.

11. American Academy of Family Physicians. Advanced Life Support in Obstetrics. ALSO International and Global ALSO. Available 
from: http://www.aafp.org/cme/cme-

topic/maternity/also/courses/ international.html

12. Dresang LT, Rodney WM, Leeman L, Dees J, Koch P, Palencia

M. Advanced life support in obstetrics in Ecuador: Teaching the teachers. The Journal of the American Board of Family Practice. 2004 Jul 1;17(4):276-82.

13. Dresang LT, González MM, Beasley J, Bustillo MC, Damos J, Deutchman M, et al. The impact of Advanced Life Support in Obstetrics (ALSO) training in low-resource countries. International Journal of Gynecology \& Obstetrics. 2015 Nov 1;131(2):209-15. 